\title{
AIAA 2002-6006
}

\section{Flow Control Research at NASA Langley in Support of High-Lift Augmentation}

William L. Sellers III, Gregory S. Jones, and Mark D. Moore NASA Langley Research Center Hampton, VA

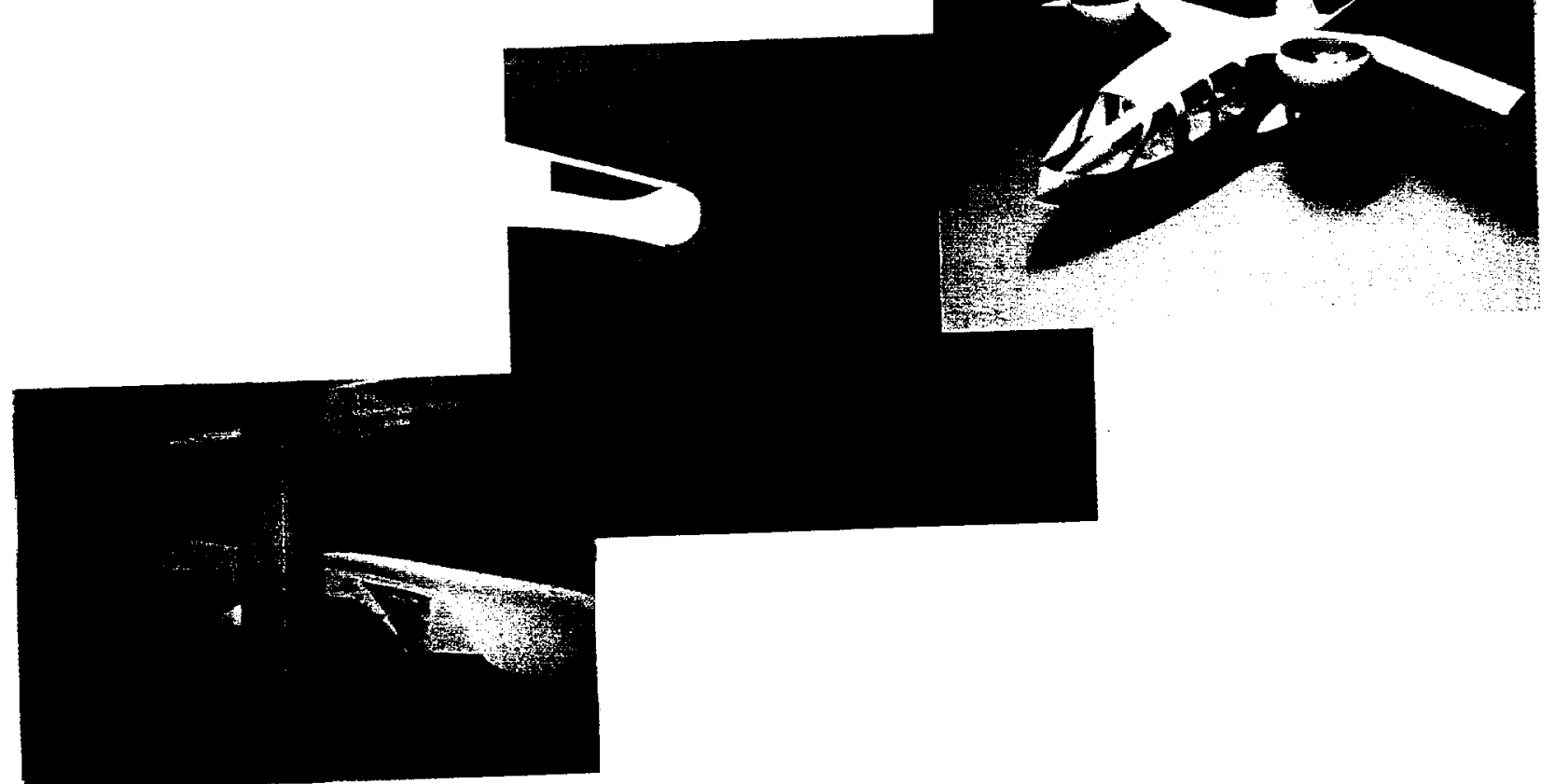

\section{Biennial International Powered Lift Conference}

5-7 November 2002

Williamsburg, VA 


\title{
FLOW CONTROL RESEARCH AT NASA LANGLEY IN SUPPORT OF HIGH-LIFT AUGMENTATION
}

\author{
William L. Sellers III , Gregory S. Jones ${ }^{\dagger}$ and Mark D. Moore ${ }^{\dagger}$ \\ NASA Langley Research Center \\ Hampton, VA 23681-219
}

\begin{abstract}
The paper describes the efforts at NASA Langley to apply active and passive flow control techniques for improved high-lift systems, and advanced vehicle concepts utilizing powered high-lift techniques. The development of simplified high-lift systems utilizing active flow control is shown to provide significant weight and drag reduction benefits based on system studies. Active flow control that focuses on separation, and the development of advanced circulation control wings ( $\mathrm{CCW}$ ) utilizing unsteady excitation techniques will be discussed. The advanced CCW airfoils can provide multifunctional controls throughout the flight envelope. Computational and experimental data are shown to illustrate the benefits and issues with implementation of the technology.

\begin{tabular}{|c|c|}
\hline b & Span (inches) \\
\hline$C_{1}$ & 2-D sectional lift coefficient \\
\hline $\mathrm{C}_{\mathrm{L}}$ & 3-D Wing lift coefficient \\
\hline $\mathrm{C}_{\mathrm{dpu}}$ & 2-D sectional profile drag coefficient \\
\hline $\mathrm{C}_{\mathrm{p}}$ & Pressure Coefficient \\
\hline c & Airfoil chord (inches) \\
\hline$c_{\mu}$ & Steady blowing momentum coefficient, $=\mathrm{J} / \mathrm{cbq}$ \\
\hline$<c_{\mu}>$ & $\begin{array}{l}\text { Oscillatory blowing momentum coefficient, }= \\
<\mathrm{J}>/ \mathrm{cbq}\end{array}$ \\
\hline $\mathrm{C}_{\mu}$ & $\begin{array}{l}\text { Combined blowing momentum coefficient }= \\
\left.\left(c_{u}+<c_{\mu}\right\rangle\right) \text { identified as (mean; oscillatory) }\end{array}$ \\
\hline $\mathrm{F}^{+}$ & Reduced frequency, $=\mathrm{f}^{*} \mathrm{X}_{\mathrm{c}} / \mathrm{U}_{\infty}$ \\
\hline $\begin{array}{l}\mathrm{J} \\
\mathrm{h}\end{array}$ & $\begin{array}{l}\text { Momentum at slot exit }=\rho_{\mathrm{jet}} \mathrm{U}_{\mathrm{jet}} \text {-hw } \\
\text { Slot height (inches) }\end{array}$ \\
\hline
\end{tabular}
\end{abstract}

"Head, Flow Physics and Control Branch, Associate +Senior Research Engineer, Member + Senior Research Engineer, Member

Copyright $C 2002$ by the American Institute of Aeronautics and Astronautics, Inc. No Copyright is asserted in the United States under Title 17, U.S. Code. The U.S. Government has a royalty-free license to exercise all rights under the copyright claimed herein for Governmental purposes. All other rights are reserved by the copyright owner.

$\begin{array}{ll}\mathrm{M} & \text { Mach number } \\ m & \text { Mass flow (lb/sec) } \\ \mathrm{U} & \text { Velocity (ft/sec) } \\ \mathrm{q} & \text { Dynamic Pressure }\left(\mathrm{lb} / \mathrm{ft}^{2}\right) \\ \mathrm{w} & \text { Slot Width (inches) } \\ \mathrm{x} & \text { Streamwise distance } \\ \mathrm{y} & \text { Vertical distance } \\ \mathrm{z} & \text { Spanwise distance } \\ \mathrm{X}_{\mathrm{te}} & \text { Distance from actuator to TE } \\ \mathrm{X}_{\mathrm{sp}} & \text { Distance from actuator to separation point } \\ \alpha & \text { Angle of attack (degrees) } \\ \delta_{\mathrm{s}} & \text { Slat deflection (degrees) } \\ f & \text { Frequency (Hz) } \\ R e_{c} & \text { Reynolds number based on chord length } \\ U & \text { Mean streamwise velocity }\end{array}$

\section{Abbreviations}

AFC Active flow control

LE Leading edge

TE Trailing edge

CCW Circulation Controlled Wing

Superscripts

Fluctuating component

\section{Subscripts}

$\begin{array}{ll}\text { jet } & \text { Conditions of jet } \\ \text { max } & \text { Maximum value during actuator blowing cycle } \\ \text { mean } & \text { Mean value } \\ \text { min } & \text { Minimum value during actuator suction cycle } \\ \text { rms } & \text { Root-mean-square value } \\ \text { AM } & \text { Amplitude modulation } \\ \infty & \text { Freestream }\end{array}$

\section{Introduction}

\section{NASA Blueprint for Aeronautics}

Aviation is currently the dominant mode of long-distance travel, and has provided substantial economic benefits to our nation. Prior to September 2001 , the traveling public dealt with periods of congestion, delays, and forecasts for increased passenger traffic and concerns about safety. Today we see an 
airline industry struggling to cope with these issues plus the increased burden of security from the threat of terrorism. The traveling public generally sees an efficient, safe air transportation system. With the projected growth in air travel we will be faced with even more congestion and serious noise and environmental issues. The aviation system is in reality a system of systems and all of these issues must be addressed together.

There is a tendency today to think that the field of aeronautics is mature and nothing more than incremental gains in performance and capacity are possible. NASA recently published their blueprint for aeronautics ${ }^{1}$ that provided a glimpse of what the future of aviation could be in the year 2050 . It addressed the challenges facings the current aviation system including capacity, safety, and security, and it outlined the importance of aeronautics to the future of our nation and the global economy. The blueprint laid out the rolc of the U.S. government in this future vision. It also stated that NASA's role was to provide enabling technology, by conducting high-risk research, developing unique facilities, and an educated workforce.

The NASA aeronautics blueprint recognized that if we meet these challenges, exciting new technologies could open up a new world of aviation. It was proposed that by utilizing the nearly 5,300 smaller airports in the United States, it would relieve the congestion at the big national hub airports and enable a new era of point-topoint travel. But as we expand to all those new airports, emissions and noise will become even more critical as a larger portion of our population becomes exposed to these issues due to increased proximity.

Revolutionary new air vehicles will be required for this new vision. This new future brings about the possibility for new large, long haul concepts, increased speed, autonomous operations, and the necessity for new vehicle concepts that provide runway independence. Runway independence will require vehicles with lightweight, high thrust-to-weight ratio, and very effective high-lift or propulsive systems. There are a number of approaches that might be taken to increase high-lift system performance and enable runway independence, and this paper will address several of the approaches taken at NASA Langley Research Center (LaRC). The effort includes both technology developments for simplified high-lift systems and circulation control and includes systems studies of advanced personal air vehicle concepts utilizing these new technologies.

\section{Langley AVSTPO program}

The technology developments applicable to high-lift systems and powered lift cuts across several of LaRC's program areas, and it would assist the reader to understand the organization involved. Washburn ${ }^{2}$ et.al, provided a snapshot of the active flow control research at NASA Langley, and the description of the research program organization that was provided is excerpted and summarized herein. The major research efforts in flow control and the required design tools are included in the Morphing and the Aerospace Concepts to Test (ASCoT) projects, which are part of the Breakthrough Vehicle Technologies (BVT) Program as shown in figure 1 .

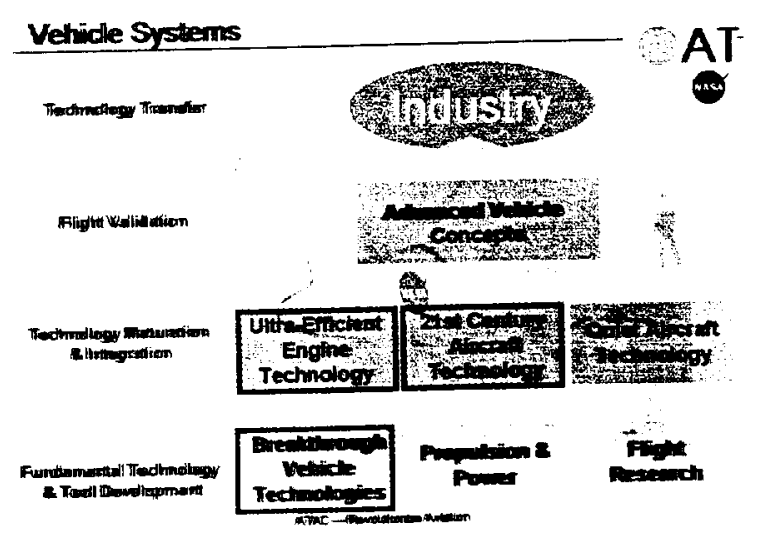

Fig. 1 NASA Vehicle Systems Program Structure from reference 2 .

Additional high-lift related flow control research is part of the Efficient Aerodynamic Shapes and Integration portion of the $21^{\text {st }}$ Century Aircraft Technologies (TCAT) Programs.

At the present time, the Morphing Project is the major source of funding for the high-lift related active flow control research. Morphing, by this project's definition, is efficient, multipoint-point adaptability and includes macro, micro, structural and/or fluidic approaches. The Micro-Aero-Adaptive Flow Control (MAAC) element of the Morphing Project is the area responsible for active separation control for efficient, simplified high-lift system. It receives support from other areas in the Morphing Project, which includes smart, nano and bio-inspired materials, multidisciplinary optimization, controls, and electronics.

The ASCOT Project is also part of the BVT Program. Since the future aeronautics vision, and highlift research in particular, is focused on the benefits of unsteady phenomena, the ASCoT Project is developing and validating time-accurate computational fluid dynamics (CFD) methodology. The ASCoT and Morphing Projects are teaming to develop the experimental databases and computational technologies required to understand and design these new high lift concepts.

The TCAT Program is under development, but the main goal is to develop and verify critical technolo- 
gies that provide significant performance improvements. The program seeks to integrate technologies developed under the BVT and other NASA Programs and provides assessment and validation of the technologies at a higher technology readiness level (TRL).

Reference 2 provided a graphical matrix of the flow control research areas under development at LaRC. There are broad ranges of technologies that are applicable to high-lift or powered lift systems and this paper will focus on the development of simplified highlift systems using either active separation control or circulation control.

\section{Separation Control}

Boundary layer separation is a critical issue in aerodynamics and fluid dynamics because it is critical to the understanding of today's real world applications. It occurs in everything from heating and ventilation systems in our home, to the engine and airframe systems of our most advanced aircraft. It is considered detrimental in most cases because it adversely impacts vehicle or component performance (e.g., pressure recovery, drag). Gad El Hak ${ }^{3}$ categorized the various control schemes in flow control based on energy expenditure. In that classification a passive device requires no auxiliary power, and an active device requires energy expenditure. The following discussion of separation control will describe the NASA Langley Research in both passive and active areas related to high-lift systems.

\section{Separation Control for High-Lift Systems}

Modern multi-clement, high-lift systems are an exceptional enginecring achievement. The process of designing a high-lift system is a lengthy and critical part of the overall vehicle design. Accurate CFD predictions of the performance of high lift systems are limited due to the inability to accurately capture boundary layer separation and Reynolds number effects. Flow separation on a conventional high-lift system is a function of the geometry and is usually very sensitive to the positioning (e.g. gap and overhang) of the various elements. Some high-lift systems may have attached flow near maximum lift conditions and separated flow at the lower (approach) angles of attack. Changing the relative gap/overlap settings can sometimes resolve the separation at the approach conditions, but adversely affect the maximum lift condition. Therefore, the high-lift designer has to optimize a number of different parameters to arrive at a balanced high-lift system design. Flow control, either passive or active, provides another tool that can be utilized to design not only higher performance systems, but simpler, lighter, and less costly systems as well.

\section{Passive separation control}

NASA Langley has a long history of research in passive separation control. The effort that has made a significant impact on high-lift systems is the development of microVG's (MVGs) by $\mathrm{Lin}^{4}$. Reference 4 provides a synopsis of the development of low profile, sub-boundary-layer scale, vortex generators. The fundamental research into MVGs occurred between 1984 and 1992 during which a wide variety of passive devices were evaluated.

The research provided two important conclusions. The first was that vortex generators on the order of $20 \%$ of the boundary layer height, $\delta$ could be very effective in delaying separation on high-lift systems. The second was that streamwise embedded vorticity provided the most efficient means of separation control. The MVG devices in the high-lift application had the added advantage of being small enough to be hidden in the flap cove during cruise conditions. During wind tunnel testing on an advanced 3-element high lift system at flight Reynolds numbers, MVGs provided a $10 \%$ improvement in lift, reduced drag by $50 \%$, and increased $\mathrm{L} / \mathrm{D}$ by $100 \%$. The results also showed that MVGs could control separation at the landing approach conditions while not adversely affecting the max lift conditions. MVGs did not provide any improvements in conditions where the flow was already attached. MVGs have seen service on various aircraft including the Piper Meridian and the Grumman Gulfstream V. As effective as the devices can be, they still suffer from the fact that they are optimized for a single flight condition. The focus of the future research in scparation control for high-lift systems will be on systems that can optimize performance over a wide range of flight conditions, and that invariably leads one to active separation control.

\section{Active Separation Control}

There has been considerable research into various schemes to control separation, and most involved steady methods or assumptions (e.g. steady blowing). In the last 15 years there has been a shift in approach to unsteady methods for separation control. An excellent review of the history, processes, and applications of separation control by periodic excitation was recently published by Greenblatt ${ }^{5}$.

For more than five years, NASA Langley Research Center (LaRC) and Tel Aviv University (TAU) have collaborated $6,7,8,10,11,12$ on the development of active separation control using oscillatory excitation. In 1998 , active separation control was demonstrated ${ }^{6}$ for the first time at flight Reynolds number. The investigation used an NACA 0015 airfoil to study both LE and TE separation control. The model was equipped with an oscillatory blowing slot at $10 \%$ chord for LE 
separation control. The model also incorporated a 30\% chord simple trailing edge flap deflected $20^{\circ}$. The flap had a blowing slot at $x / c=0.70$ (stowed coordinates) to investigate flap separation control. The results for the leading edge flow control, shown in figure 2, extended the low Re taken at Tel Aviv to Re up to $31 \times 10^{6}$. The test data from TAU was at $R_{c}=0.9 \times 10^{6}, M=0.12$, and $C \mu=(0.10 ; 0.03) \%$. The LaRC data was at $R_{c}=37.6 \times 10^{6}, M=0.3$, and $C \mu=(0.27 ; 0.05) \%$. The results demonstrated that when normalized by $C_{\operatorname{lmax}}$, there was no significant $R_{e}$ dependence on the lift benefits with separation control.

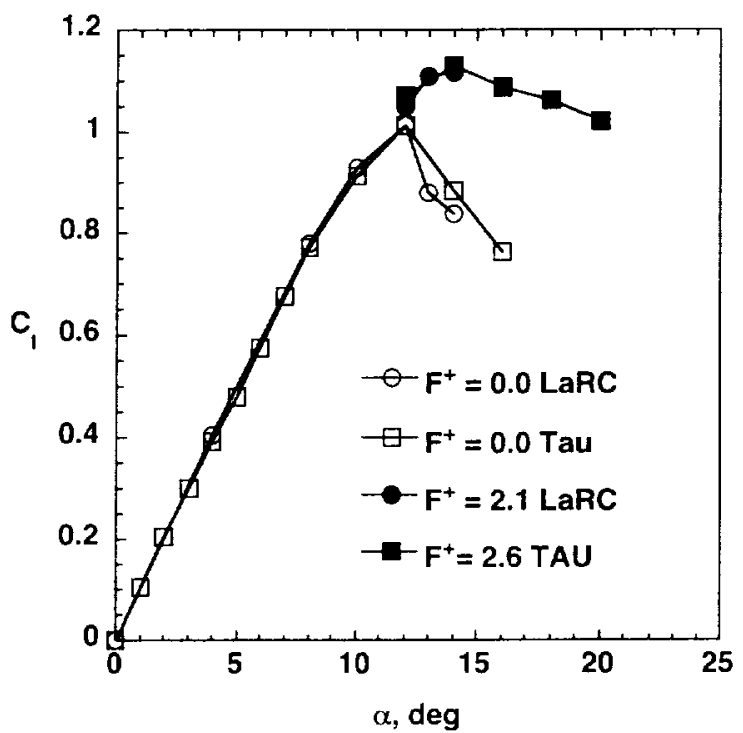

Fig. 2 Comparison of Reynolds number effects on LE separation control

The benefits included an increase in $\alpha$ at $\mathrm{C}_{\operatorname{lmax}}$ of $2^{\circ}$ and a milder stall than the baseline airfoil. In the case of the flap, the data in figure 3 shows that $\mathrm{F}^{+}$and $\mathrm{C}_{\mu}$ were not affected by Reynolds number. It also shows the significant increase in lift for a fixed $\mathrm{a}=4.0^{\circ} . \quad \mathrm{An} \mathrm{F}^{+}=0.7$ was effective in fully reattaching the flap at low angles of attack, but the effectiveness decreased at higher angles of attack. This was caused by $\mathrm{F}^{+}$being tuned to the lower $\alpha$ 's, and insufficient $c_{\mu}$ for the higher angles. Perhaps the most important finding from this investigation was the fact that oscillatory blowing was more than two orders of magnitude more effective than steady blowing. This is illustrated in figure 4 , where for a $C_{1} \approx$ 1.0 oscillatory excitation required a momentum coefficient of only $0.03 \%$ compared with $2.7 \%$ for steady blowing.

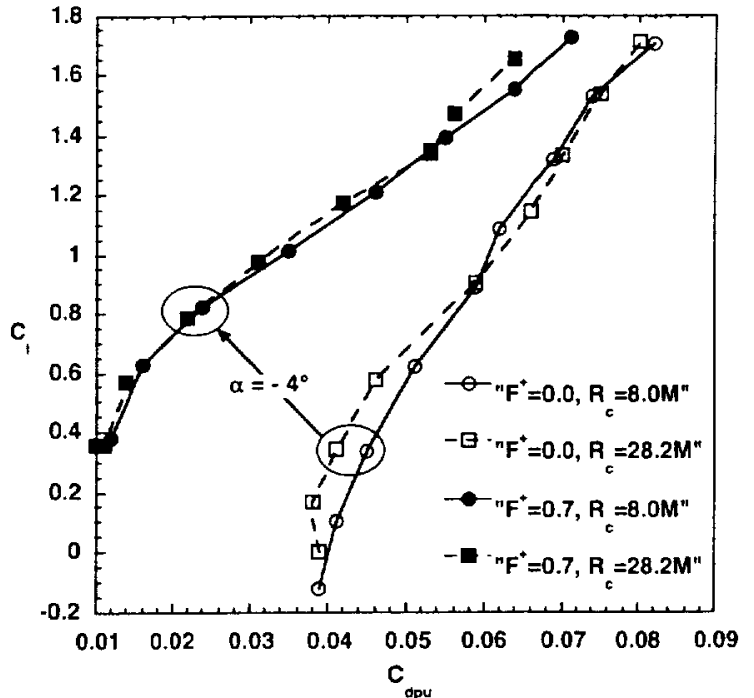

Fig. 3 Lift-form drag polars for $\delta_{f}=20^{\circ}, M=0.2$, and $\mathrm{C}_{\mu}=(0.0 ; 0.05) \%$

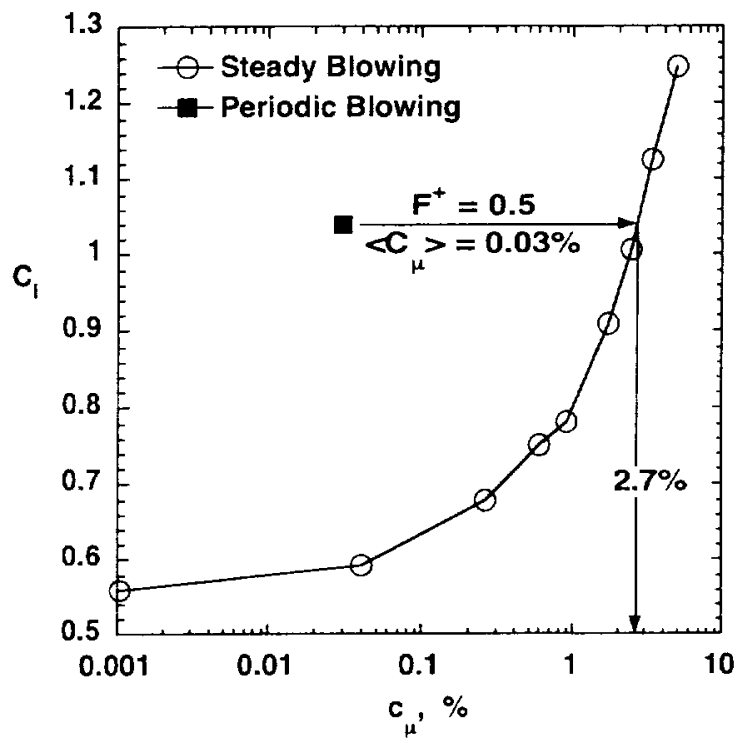

Fig. 4 Comparison between steady and unsteady blowing for flap separation control

The results from this investigation were so promising that NASA LaRC contracted with the Boeing Company to put together a team to conduct a system study ${ }^{13}$ of oscillatory blowing for separation control. They examined a number of potential applications, and identified high-lift separation control as the highest priority. The study team relied on unsteady separation control to only match the performance of a conventional high lift system. The major benefits would therefore come from developing a simpler, lighter, and less costly system based on flow control. Their concept of a simplified high-lift system evolved to a system with a 
simple hinged drooped leading edge and simple hinged trailing edge flaps. Their estimates of potential benefits were based on applying active flow control to both LE and $\mathrm{TE}$ devices. Their benefit assessment demonstrated potential reductions including a $2.6 \%$ in part-card count, $3.3 \%$ in empty weight, and $1.3 \%$ in manufacturing cost. These benefits combined to provide a $3.3 \%$ reduction in drag due to a simpler and lighter high-lift system. The system study provided several recommendations as to future research based on their experience in the study. A high-lift system utilizing active flow control would require flap deflections between $50^{\circ}$ and $60^{\circ}$. That was beyond the range of all available data therefore, it was recommended that additional research be focused in that range. In addition, no data was available for active separation control with drooped LE's devices. Lastly the team recommended that a study of separation control with simultaneous LE and TE blowing was needed to determine if there were adverse interactions.

At NASA LaRC there were concerns regarding compressibility and sweep effects, and excitation mode that needed to be addressed, since all could become issues in a viable high-lift system. A limited investigation? of compressibility and dynamic effects utilized the earlier 0015 model with LE blowing to assess oscillatory excitation in the presence of shocks, and to examine dynamic effects in the wake. The investigation showed that similar to low $\mathrm{R}_{\mathrm{c}}$ experiments with incompressible flow, $\mathrm{C}_{\operatorname{lmax}}$ increased by $15 \%$, post stall lift increased by $50 \%$, and drag was reduced by $50 \%$ in compressible flows. Figure 5Fig. 5 shows typical results comparing the lift from the Mach 0.28 and 0.4 cases.

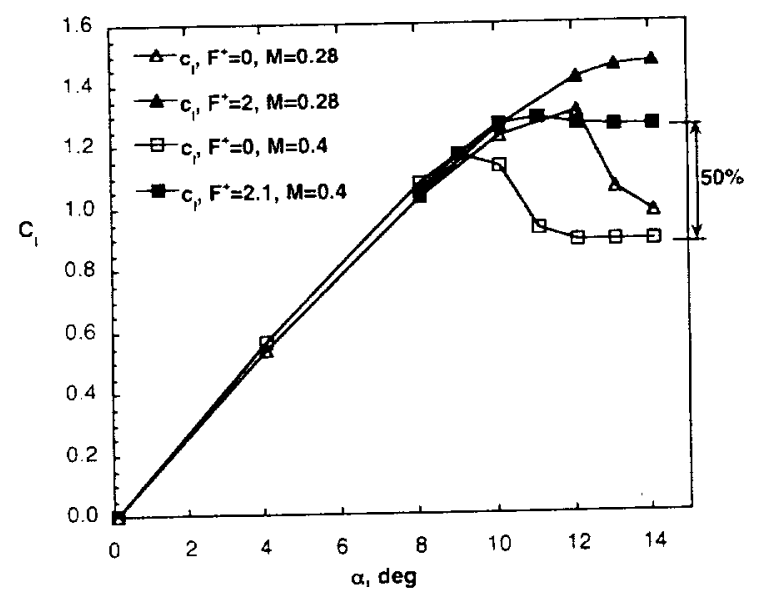

Fig. 5 The effects of Mach number and excitation on the lift of the NACA 0015 airfoil, $R_{c}=12.7 \times 10^{6},\left\langle c_{\mu}>\right.$ $=0.03 \%(M=0.28)$ and $0.0245 \%(M=0.4)$

The results were sensitive to the excitation location. If excitation was well ahead of the shock location it had a detrimental effect on airfoil performance, due to the creation of a second shock wave at the blowing slot. When excitation was applied slightly ahead of the shock it proved beneficial regardless of the Mach number.

Further investigations ${ }^{8,9,10}$ of compressibility and sweep effects were conducted with a new "hump" model. The model derives its name from the fact that it uses the coordinates of the upper surface of a Glauret Glas II airfoil and is mounted on the tunnel sidewall to form a "hump" as shown in figure 6. The experiments were conducted in the LaRC 0.3 -meter Transonic Cryo Tunnel $^{14,15}$ (TCT).

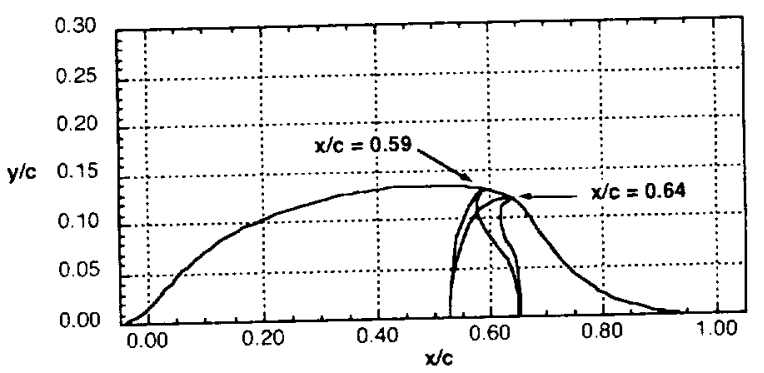

Fig. 6 Hump model geometry and blowing slot locations

The original location of the wing leading edge is designated as $x / c=0.0$ and the region between $-0.05<$ $\mathrm{x} / \mathrm{c}<0.05$ was faired smoothly into the tunnel floor to avoid separation at the leading edge. This smoothing had a dual effect. First it prevented separation at the wing leading edge, and second it meant that the model would be fully turbulent due to the upstream turbulent wall boundary layer. The airfoil thickness was $20 \%$ of the root chord and without flow control the flow separates at $x / c=0.65$ both with and without sweep. Oscillatory excitation slots were placed at $x / c=0.55$ and $\mathrm{x} / \mathrm{c}=0.64$.

The results of this investigation showed that steady suction or blowing with a momentum coefficient ranging from $2 \%$ to $4 \%$ was required to fully reattach the flow and recover the predicted ideal pressure distribution. Oscillatory excitation was comparable to steady suction in effectiveness and significantly more effective than steady blowing. Although periodic excitation was capable of reattaching the flow, it is not capable of reproducing the same pressure jump that steady suction produces across the excitation slot. Figure 7 shows that the superposition of a slight amount of steady suction with periodic excitation enhances the receptivity of the shear layer and produces better results. 


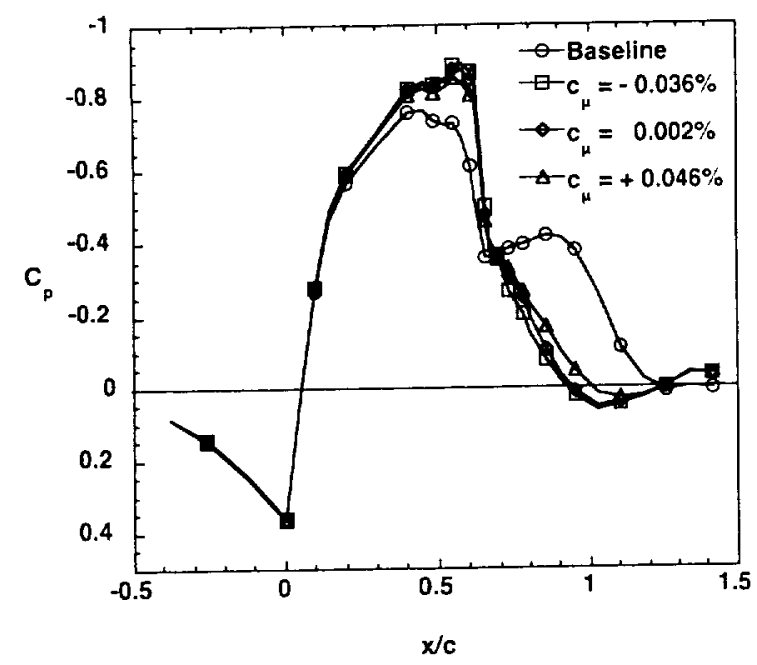

Fig. 7 The effect of steady blowing and suction on periodic excitation, $\mathrm{F}^{+}=1.15, \quad<\mathrm{c}_{\mu}>=0.23 \%$, $R_{c}=16 \times 10^{6}, M=0.25$

Sweep and additional compressibility data were documented ${ }^{10}$ in a follow-on investigation. The results shown in figure 8, illustrate that compressibility tends to elongate the separation bubble due to rcduced mixing above the separated region. Periodic excitation is capable in reducing the separation bubble at compressible speeds however; its effect is reduced when using the frequencies and excitation levels used at incompressible speeds.

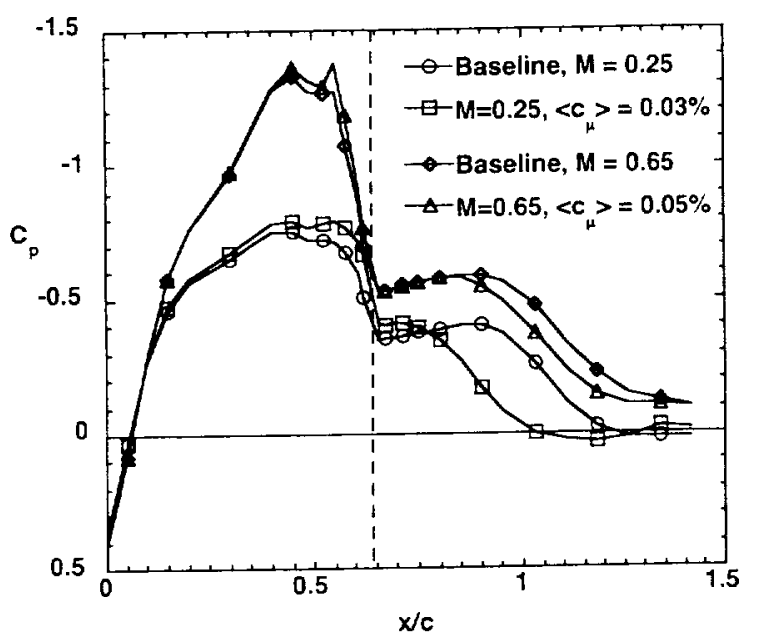

Fig. 8 Comparison of control effectiveness at compressible speeds, $M=0.65, R_{c}=30 \times 10^{6}, F^{+}=0.3$, and $\mathrm{M}=0.25, \mathrm{R}_{\mathrm{c}}=16 \times 10^{6}, \mathrm{~F}^{+}=0.4$

An investigation of the use of oscillatory blowing based on a modern supercritical wing has begun to answer the remaining questions from the Boeing systems study. The NASA Energy Efficient Transport (EET) airfoil ${ }^{16}$ was chosen as the baseline. The model was equipped with a $15 \%$ chord simple-hinged drooped LE, which will be referred to as a leading edge slat and a $25 \%$ chord simple-hinged trailing edge flap. A comparison between the cruise configuration data with results taken previously at the NASA Langley Low Turbulence Pressure Tunnel (LTPT) was very good.

The model was constructed in a modular fashion that provided the insertion of flow control actuators at several locations as shown in figure 9. The LE and trailing edge flap settings were all computer controlled. The LE slat could be deflected to $-30^{\circ}$ and the trailing edge flap could be deflected to $-60^{\circ}$. A photograph of the model installed in the NASA Langley Basic Aerodynamics Research Tunnel (BART) with the LE and TE flaps deflected is shown in figure 10 .

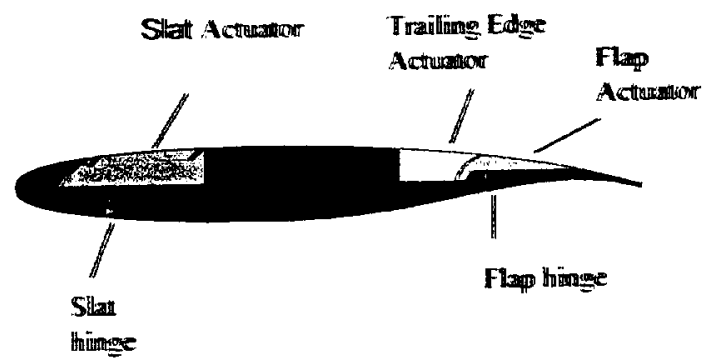

Fig. 9 Modular EET model used for experiment, $c=406.4 \mathrm{~mm}$

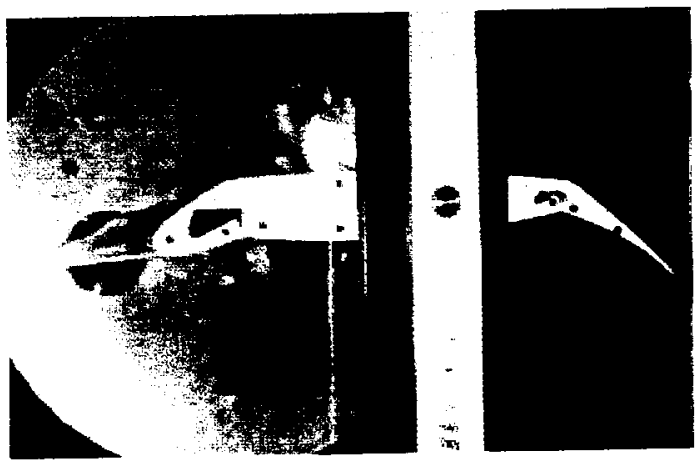

Fig. 10 Simplified high-lift version of EET airfoil model installed in BART

The results using LE slat flow control was published in reference 12 . The slat actuator had two blowing slots located at $x / c=0.14$ and $x / c=0.3$. The forward slot was hidden under the main element at the stowed condition to eliminate any actuator cavity interactions with the freestream. A well-optimized airfoil might suffer from discontinuities caused by blowing slots, and the results showed that up to $C_{\text {Imax }}$, there was no measurable effect. An investigation of the baseline (e.g. no AFC) performance of the LE slat was as expected. The results in figure 11 show that slat deflection increased maximum lift by $12 \%$. The angle 
at which stall occurs is delayed by approximately 4 degrees. The effect of AFC was to increase the lift by another $12 \%$.

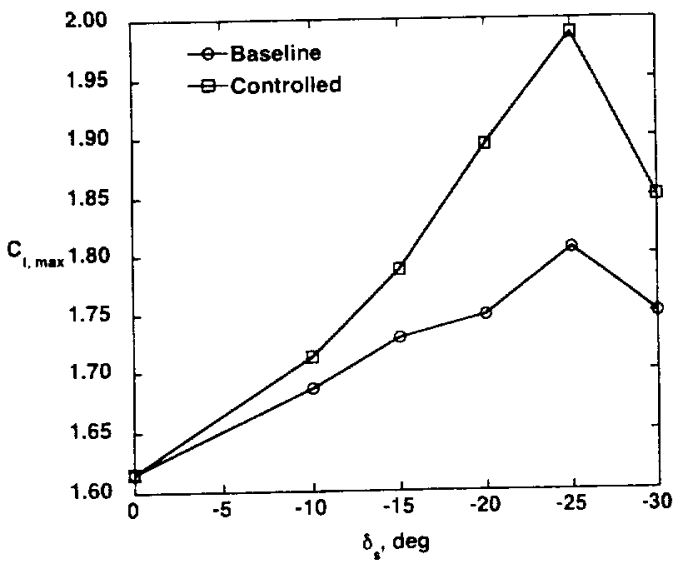

Fig. 11 The effect of flap shoulder flow control on lift

During the test different types of excitation were investigated. Previously actuators were typically driven by a continuous sine wave at varying frequencies and amplitudes. The actuation frequency is typically the resonant frequency of the piezoelectric diaphragm and in this case was either $853 \mathrm{~Hz}$ or $1 \mathrm{KHz}$ depending on the type of piezo element installed. It is a balancing act trying to match the actuator frequency with the optimum $\mathrm{F}^{+}$for separation control. In this test the actuator was also driven using an amplitude modulation $(\mathrm{AM})$. This technique allows you to operate the piezo actuator at its optimum frequency and tune the separation control to appropriate $F+$ using the AM modulation. Figure 12 shows a comparison of the effect of AM modulation for different values of $\left\langle c_{\mu}\right\rangle$ on the lift. The results showed that clearly AM modulation was more effective and required $50 \%$ less $\left\langle c_{\mu}>\right.$ for the same lift coefficient.

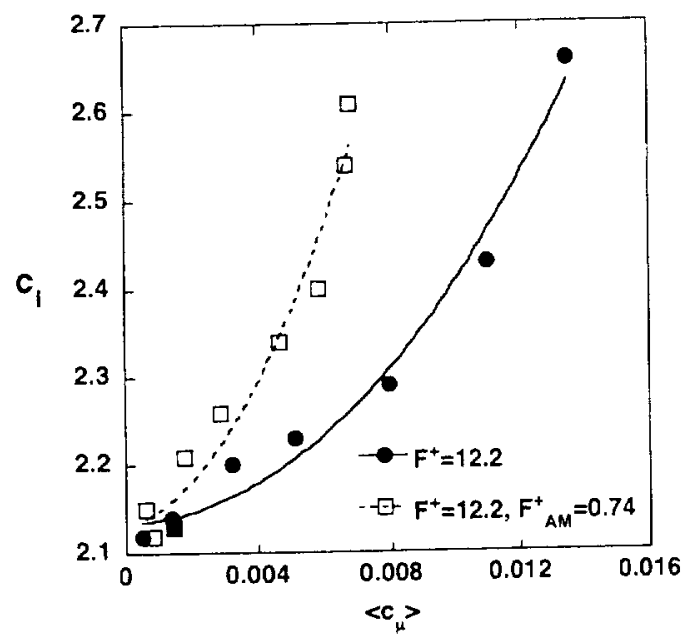

Fig. 12 The effect of excitation modulation on lift
Additional testing is underway at NASA LaRC documenting the effect of oscillatory blowing on TE flap separation, and combined LE and TE blowing. Plans are underway to construct a larger model for testing in the LTPT tunnel. This facility is designed specifically for 2-D airfoil testing and the larger size will remove some of the current limitations previously encountered with the actuator placement in such small elements.

\section{Circulation Control}

The aerodynamic characteristics of Circulation Control Wings (CCW) have been experimentally and numerically studied. ${ }^{17,18,19,20}$ for more than 65 years. The benefits of CCW have also been highlighted in flight tests that focus on high-lift. In spite of significant improvements in performance, CCW techniques have not been applied to production aircraft. Many of the roadblocks to this technique include engine bleed requirements, and cruise performance penalties. LaRC has three current research efforts that focus on developing CCW technologies, 1) pulsed pneumatic flaps for general aviation, 2) pneumatic diffusers for distributed engines, and 3 ) channel wing.

Traditionally Circulation Control Wings (CCW) are restricted to a pneumatic modification of the flow field through a Coanda effect ${ }^{21}$ as shown in figure 13 . The wall bounded jet flows along the surface and has the nature of a boundary layer near the wall but becomes that of a free jet at a larger distance from the wall. $^{22}$ The degree of jet turning can be related to the slot height, surface radius, jet velocity, and the Coanda surface geometry.

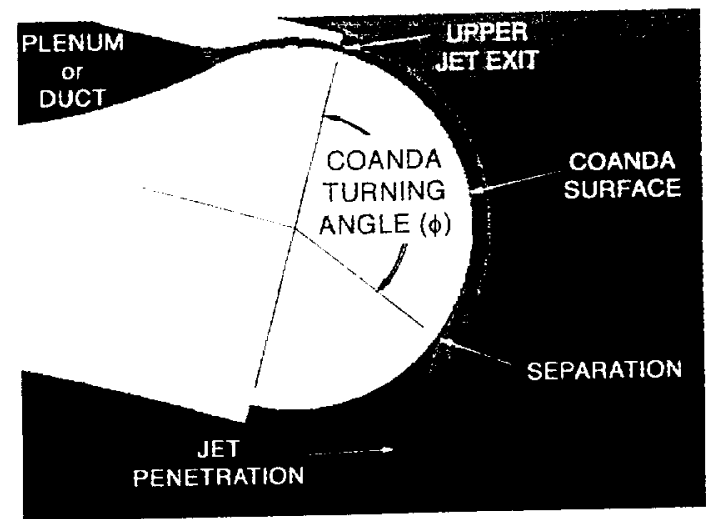

Fig. 13 Example of Coanda effect

Appling the Coanda effect to the trailing edge of an airfoil results in streamline turning similar to that of a traditional flap/slat high lift system. Figure 14 shows a CFD simulation that highlights streamline turning that is characteristic of $\mathrm{CCW}$ techniques. Nominally the streamline turning can be related to Lift performance 
through the integration of the circulation around the airfoil. It is important to recognize that the flow control related to the Coanda effect is broken into separation effects and super-circulation control effects. This can be identified by the jet separation on the Coanda surface and the jet penetration into the free stream.

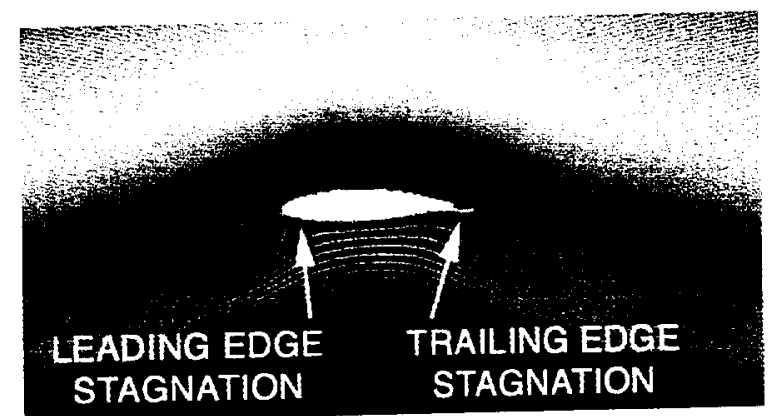

Fig. 14 CFD simulation of streamline turning

Both of these parameters are dependant on the jet velocity ratio and Coanda surface and the airfoil leading edge geometries. The resultant lift performance characteristics also highlight the limits of separation control and the effect of super-circulation as shown in figure 15.

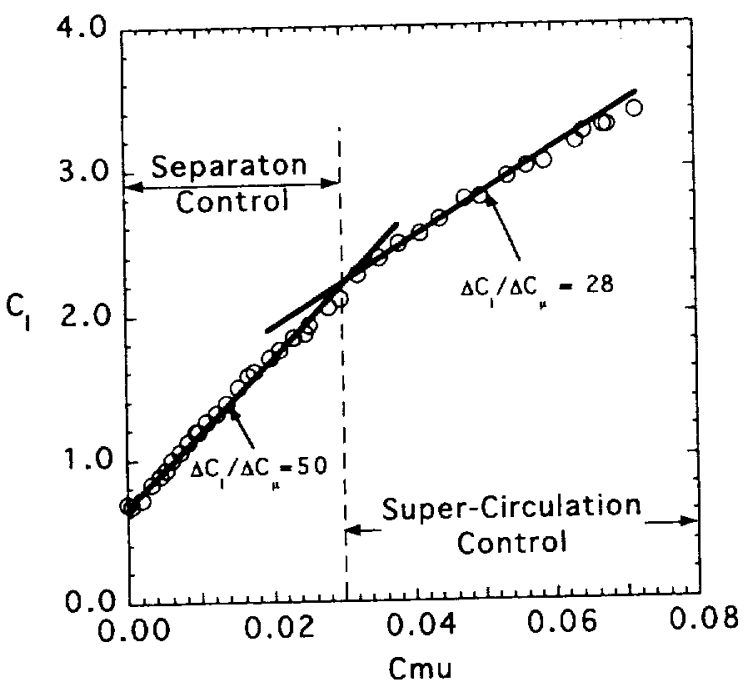

Fig. $15 \mathrm{CCW}$ Lift augmentation through separation and super-circulation flow control for GACC airfoil

\section{AFC Pneumatic Flap (GACC)}

The LaRC General Aviation Circulation Control (GACC) Wing research effort is intended to address technology issues, such as scaling, mass flow, and noise requirements. A 2-D flow physics supercritical airfoil model $^{23}$ (figure 16) with dual slotted circulation control capability has been designed and built for low speed testing in the BART Tunnel. The primary objective of the program is to evaluate the benefits of pulsed circulation control to reduce the mass flow requirements for a given lift performance as well as reduce the cruise drag penalty associated with a large circulation control trailing edge.

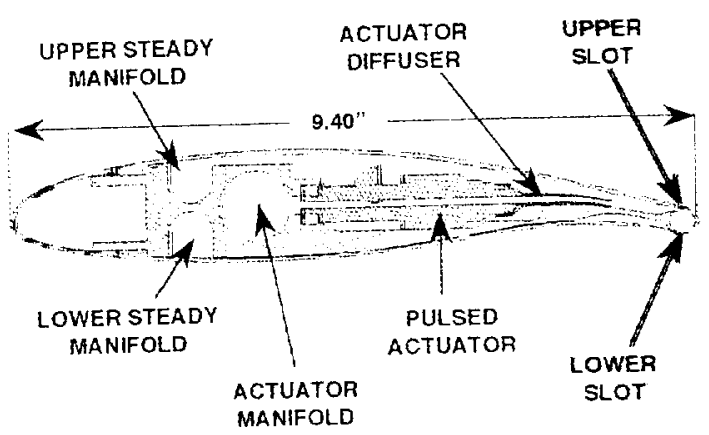

Fig. 16 Two-Dimensional 17\% Supercritical General Aviation Circulation Controlled Airfoil with a circular trailing edge, $r / c=2 \%$

The optimization of high lift and cruise performance with one airfoil shape gives rise to the pneumatic flap concept ${ }^{24,25}$ This concept is based on the ability to switch from a high lift configuration to a cruise configuration without utilizing any mechanical systems. Having two independent blowing systems allows one to have such a multi-function system that can be used for high lift systems and flight control systems such as ailerons and air brakes. Moving from a high lift to a cruise configuration is dependent on the upper and lower blowing ratios and the free stream velocity, and can be optimized for minimum cruise drag.

It was important to establish a baseline using steady blowing to determine the effectiveness of pulsed circulation control. The effectiveness of the pulsed pneumatics is referenced to the steady blown $\mathrm{CC}$ conditions at $\alpha=0.0$ degrees. The baseline performance of the GACC model is characterized by the lift as shown in figure 17. The GACC experimental lift results evaluated at an angle of attack of zero will provide lift augmentation, $\Delta C_{L} / \Delta C_{\mu}=50$. This is consistent with other small trailing edge $\mathrm{CCW}$ airfoil experiments. The test matrix was limited to lift coefficients of approximately 3 . This was consistent with general aviation requirements for an aircraft with a wing sized for cruise conditions and still be able to meet FAR stall requirements. It also limited the wall interference of the GACC model in the BART tunnel. 


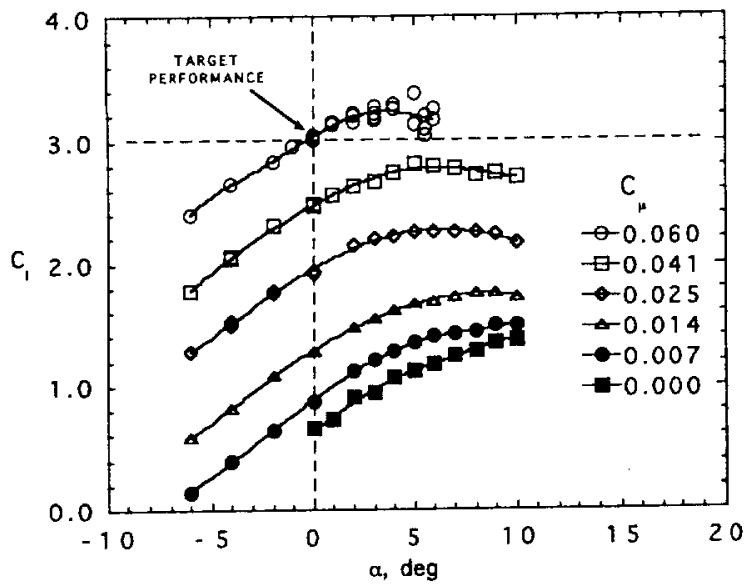

Fig. 17 Lift characteristics of the 2-D GACC airfoil using steady blowing

\section{Dual Blowing}

To minimize the drag the GACC airfoil is equipped with upper and lower blowing on the Coanda surface. In principle the pneumatic flap is optimized for drag when the upper and lower Coanda jets close the wake with minimum momentum losses. This occurs when the upper and lower jets remain tangential. If the two jets turn around the Coanda surface and impact upon one another the flow will rebound creating a larger wake and increase in drag. This occurs at jet velocity ratios above 2 . The trends in dual blowing efficiency, shown in figure 18 , demonstrate a potential $20 \%$ improvement in $\mathrm{L} / \mathrm{D}$ at an $\mathrm{AOA}$ of zero degrees.

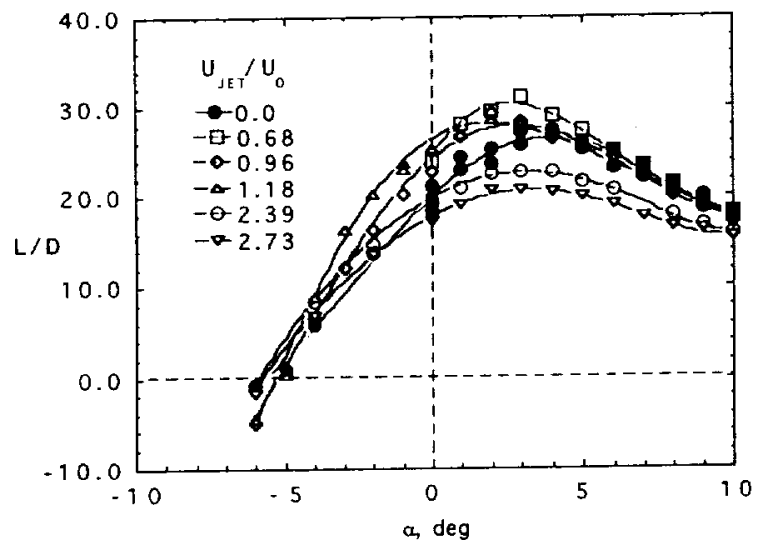

Fig. 18 Dual blowing Lift to Drag ratio $(h=0.01)$

\section{Pulsed Blowing}

The effectiveness of pulsed blowing on the performance of the GACC airfoil is dependent on the efficiency of the actuator system. This system must include the actuator performance, diffuser performance, and the response of the internal volume prior to the jet exit as well as the external time dependent Coanda effectiveness. Ideally the time dependent Coanda response would resemble the steady state blowing series. This would assume a perfect square wave response at the jet exit. The reality of a perfect square wave diminishes with the complexities of the actuator system.

The response of the state-of-the-art high-speed actuator valves used for this study does not generate a perfect pulsed ${ }^{26}$ waveform. Transmitting the pulse through the nozzle and into the nozzle exit distorts the waveform as shown with thin film data located at the nozzle exit. For the low frequency pulsed jet, the effect of duty cycle is shown in figure 19.

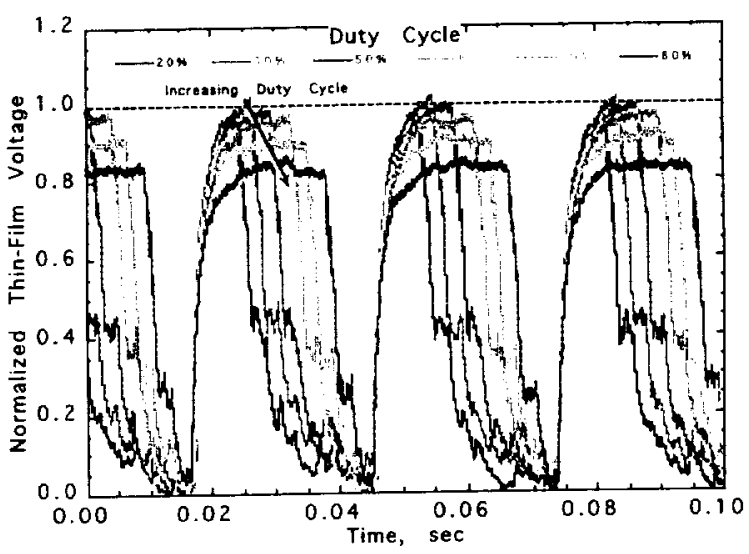

Fig. 19 Normalized thin-film time history for pulsed CCW at the slot exit, $h=0.020$, and driver frequency $=35 \mathrm{~Hz}$

The peak amplitude for the low duty cycle conditions $(20 \%$ and $30 \%)$ does not reach the maximum output performance of the actuator system. The actuator valve being closed before the plenum and actuator volumes have had time to be fully pressurized causes this result. Once the valve is given a close command the plenum remains pressurized and continue to bleed air through the jet exit until the plenum pressure reaches ambient conditions.

As the drive frequency is increased, figure 20 shows that the rise time or valve opening distortions increase. For the closed portion of the duty cycle, air continues to bleed from the plenum until the open command is given, resulting in the jet velocity not going to zero. This process limits the mass flow to the jet exit as indicated by an overall reduction in the peak velocity. In spite of the limitations of the actuator system, the peak velocities do approach sonic conditions. 


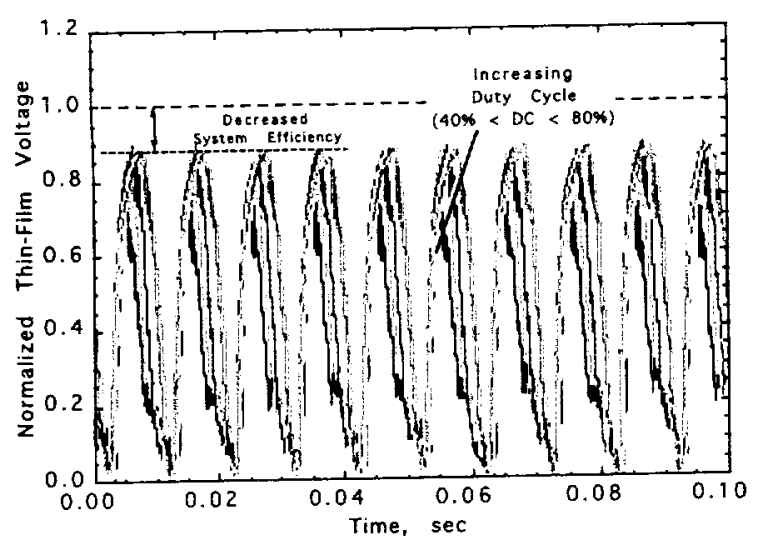

Fig. 20 Normalized thin-film time histories for pulsed $\mathrm{CCW}$ at the slot exit, $h=0.020$, and driver frequency $=100 \mathrm{~Hz}$

These data are consistent with conditions measured for both slot configurations. For low frequency pulsed jets, the frequency characteristics of the jet can be separated into pulsed and turbulence regimes. The transition from the pulsed to the turbulence regime seemed to be independent on the jet velocity and occurred near 300 $\mathrm{Hz}$.

Comparing the pulsed and steady lift performance of the GACC airfoil, figure 21 , a distinct improvement in lift or mass flow required can be seen. For a given lift coefficient of 1.0 , a $48 \%$ reduction in mass fow is realized for a $20 \%$ duty cycle. As the duty cycle is increased the performance benefit decreases. Comparing the lift performance of the pulsed and steady CCW at a fixed mass now of 25 SCFM results in a $35 \%$ lift improvement.

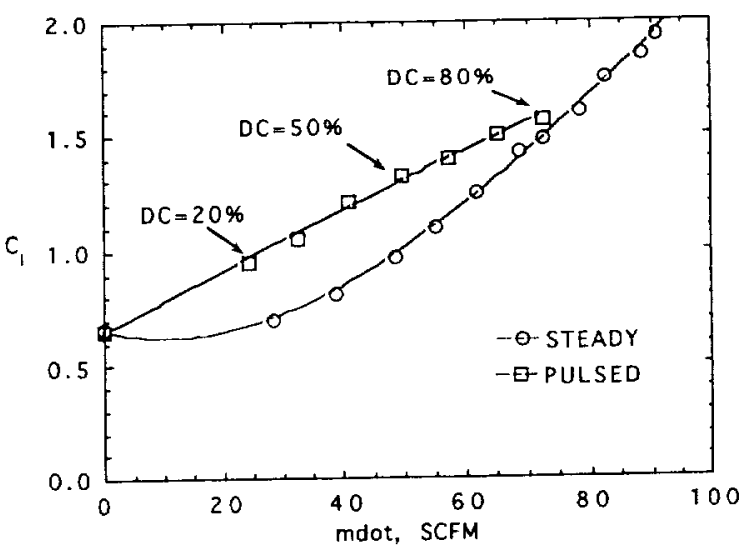

Fig. 21 Comparison of pulsed and steady circulation control, frequency $=35 \mathrm{~Hz}$, and varying duty cycle

\section{Future Applications}

The Langley research Center (LaRC) was chartered by the NASA Administration to be the lead NASA Center for evaluating revolutionary aerospace system concepts (RASC) and architectures to identify new mission approaches, and associated technologies that enable these missions to be implemented. This effort includes experts from the various field centers, academia, and industry. Although RASC conducts many studies across the NASA Enterprises, the Personal Air Vehicle Exploration (PAVE) study has direct application to powered lift research and configurations.

The objective of PAVE is to explore future mobility requirements aimed toward a system solution for door-to-door personal travel. The improvements in lifestyle for the traveling public would be significant as highlighted in figure 22. Small companies have tried to develop personal air vehicles (PAVs) that blend the functions of an automobile and an airplane for more many years, but typically with minimal investments in advanced technologies to solve the inherent problems. They proposed or built various vehicle concepts that would either break apart, fold, or were Vertical Takeoff and Landing (VTOL) concepts.

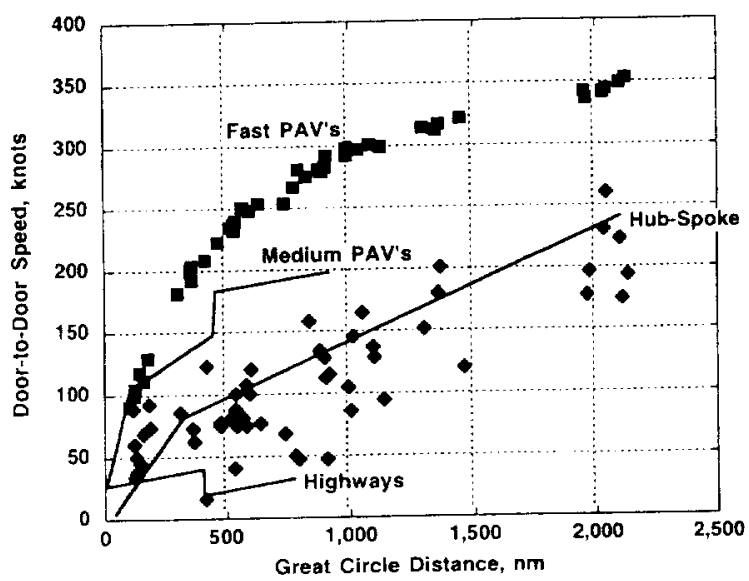

Fig. 22 Door to door travel time by mode

NASA's PAVE project is approaching this effort differently from prior efforts by studying the PAV concept through a "systems" approach with identification of the key enabling technologies and the potential benefits as investments bring about these technologies. These new vehicle concepts fill a matrix from Conventional Takeoff and Landing (CTOL), to Short Takeoff and Landing (STOL), to Extreme STOL, VTOL, and from single aerial use only concepts to dual-use (roadable) concepts. This matrix trades off complexity and cost with the ability to achieve a nearer door to door transportation system. As mentioned in the NASA Blueprint, these new PAV concepts will have to be extremely safe and simple for use by nonprofessional pilots. They will require very low takeoff and landing speeds. Because of their projected wide use, they must be environmentally friendly with low 
noise and automotive equivalent emissions. Cost will be a big factor in the development of PAVs as the vehicles must provide a positive return on investment compared to an individual's value of time. Lastly the vehicles must be sized to fit into the limits imposed by existing infrastructure. Not to minimize the importance or difficulties in the revolutionary changes required in the airspace system itself, the rest of this discussion will focus on vehicle technologies required for PAVs.

Part of the PAVE study objective was to explore the PAV design space, which included defining, establishing, and integrating synergistic technologies based on a 2015 TRL. To accomplish this task it is necessary to develop advanced concepts utilizing physics based methods, and comparing concepts to 1 ), reference baselines, 2) each other, and 3) alternate travel modes. An important output from this approach is an identification of the sensitivities, and the gaps in various technologies.

At this stage in the project, the study has broken down the vehicle technologies into subsystems that include propulsion, aerodynamics, aero-propulsive systems and controls, and structures categories. One must keep in mind that many of these concepts are highly integrated and all four of these areas must be worked simultaneously. Propulsion technologies include reciprocating engines with increased specific output, lightweight and low-noise turbofan and turboshaft engines, distributed propulsion mini-engine systems, and electric propulsion systems.

PAV concepts vary from the mild to the wild, and Circulation Control (CC) has been applied across this range because of the inherent low takeoff and landing speeds involved in these missions. Circulation Control is most effective at lower velocities since the key driving parameter is the jet velocity compared to freestream velocity ratio. Thus, lower takeoff and landing velocities can utilize lower jet velocities or lower mass flows while achieving the same effective lever-arm on the maximum lift. Examination of current General Aviation (GA) baseline vehicles show that the 61 knot stall rule has locked these aircraft into low wing loading solutions, which are highly susceptible to gust concerns, and result in wings that are considerably larger that that desired in cruise. As an example, current GA aircraft achieve an L/D of approximately 10 to 12 at cruise, even though their $L / D_{\max }$ is about 17 . Applying complex and expensive high lift systems as in transport aircraft is not a solution that will carry well to this marketplace, or to the experience level of GA operators. One of the simplest uses of Circulation Control applies the GACC airfoil with the utilization of a turbocharger to power the pressurized blown plenum. Since turbocharging is merely used for altitude compensation in GA aircraft, and not increased power at takeoff, all the turbocharger compressed air is dumped out a waste gate at this condition. Thus a no cost air supply is present, with air mass flow on the same order as are required for a moderate performing CC system. Another key concern becomes the ability to achieve high lift without engine power, and thus without the turbocharger air supply. Reservoir air plenums would require a significant weight for even the minimum several minute capacity. However, the use of slow burn, solid rocket gas generator offers a much lighter emergency-only solution. The resulting wing weight reduction more than compensates for the valves, emergency system, and ducting required for the $\mathrm{CC}$ system, providing a lighter, smaller, and more compact wing. Circulation control could potentially be highly synergistic in several more exotic application areas, including the use of distributed propulsion systems. Two examples of NASA PAVE concepts that utilize advanced preumatics in a highly synergistic fashion will be described below.

\section{Channel Wing}

NASA in collaboration with Georgia Tech Research Institute is revisiting the channel wing concept ${ }^{27.28}$, to develop very high lift for Extreme STOL (ESTOL) applications, but with a very simple system, that has no externally moving parts. The powered-lift Channel Wing concept combines Circulation Control aerodynamic and propulsive technologies to provide a Pneumatic Channel Wing configuration intended to have ESTOL or perhaps even near VSTOL capability, but without the ability to hover. The application of $\mathrm{CC}$ to the channel wing solves an important problem of the original channel wing concept. While the channel section was essentially stall-proof, generating increasing lift up to 45 degrees angle of attack, this lift was unusable in takeoff or approach becausc of limited tail scrape angles of the fuselage (typically about 12 degrees). The use of CC provides increased channel circulation lift in a large streamtube, at usable angles of attack. A preliminary design study of this pneumatic vehicle is based on previous wind tunnel and flight-test data. Advanced flow control technologies are integrated into a simple Pneumatic Channel Wing (PCW) configuration, shown in figure 23. Preliminary wind-tunnel development and evaluations of a $\mathrm{PCW}$ powered model have shown substantial lift capabilities for the $\mathrm{CCW}$ blown channel wing configuration ${ }^{29}$. $\quad C_{\text {LMAX }}$ approaches 8.5 to 9.0 using just the channel portion of the wing, i.e. no outboard blowing. The blown model also showed the ability to interchange thrust and drag by varying blowing to provide greater flexibility in Super STOL takeoffs and landings. Adding the outboard CCW w/ pulsed trailing edge pneumatics is expected to increase the high lift performance and provide improved flight control capability. 

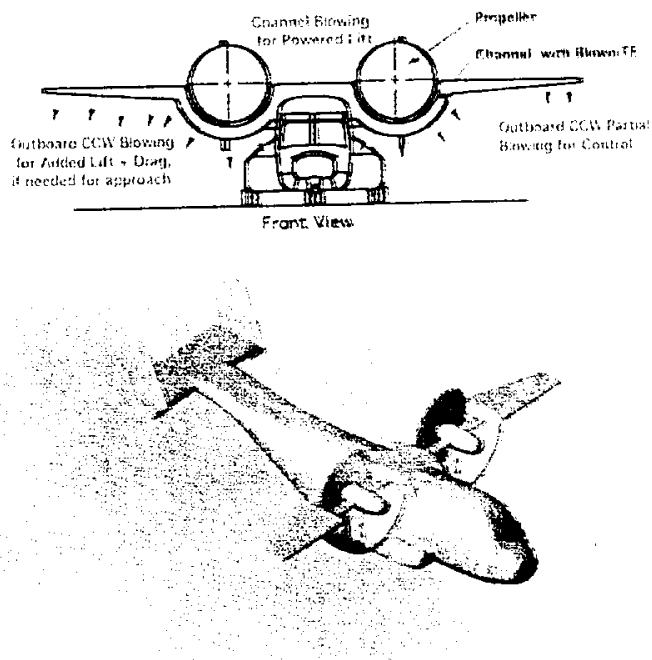

Fig. 23 Artist drawing of a powered lift channel wing with a $C C W$ aircraft concept

Distributed Propulsion

Pneumatic control and distributed engine technologies are being applied to a tilt nacelle concept based on the Grumman 698 design. The concept shown in figure 24 , utilizes thrust vanes to generate all hover control authority. In addition, the concept uses pneumatic nacelles that provide pneumatic morphing of the nacelle allowing a virtual tailoring of the inlet and exhaust flow pattern. This will enable the designer to maximize the propulsion system performance throughout the flight envelope. Additional benefits include a reduction in the effective hover disc loading at the ground plane and a reduction in the ground erosion and foreign object damage (FOD) constraints.

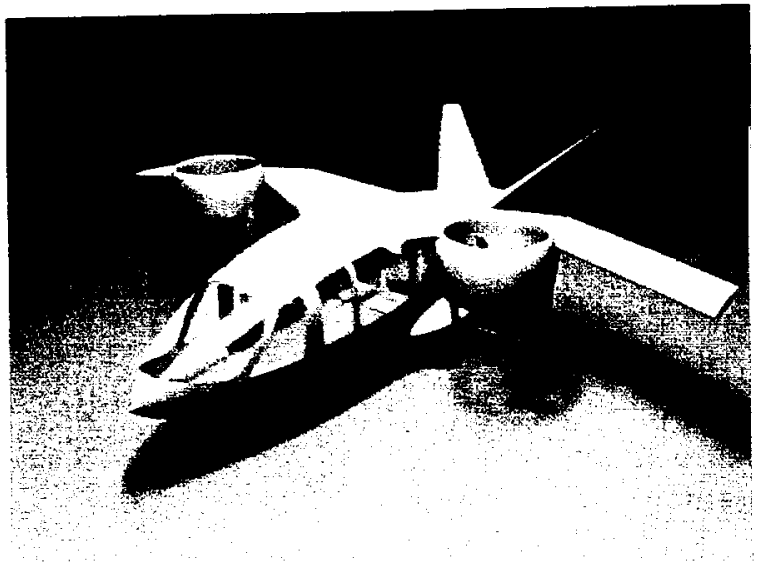

Fig. 24 Personal Air Vehicle Concept utilizing circulation control nacelles

The Multi-Gas Generator Fan (MGGF) shown in figure 25 , is based on a concept that uses the exhaust of several smail engines to drive a tip driven fan, then ducting the flow onto a Coanda surface for pneumatic control of the diffuser. Coupling the pneumatic nacelle with the MGGF concept provides the smallest propulsion system power requirement possible for V/STOL. The MGGF provides a relaxing of the engine-out in hover approach sizing constraint which determines the engine size, dramatically reducing the required thrust to weight of the vehicle from approximately 2.4 for a twin engine concept, to about 1.4 for MGGF concept while also eliminating the need for an engine cross-shafting system. The pneumatic nacelle provides maximum hover nacelle entrainment and lip suction for a cruise shaped nacelle in the hover sizing condition. It also provides nacelle separation control in transition and crosswind conditions. There are penalties involving a more complicated fuel routing system and fan redundancy. A recent study showed that only $4 \%$ of all propulsion system problems were related to the fan, while $71 \%$ were due to gas generators making the redundancy of the MGGF a potentially safer systcm. The combination of these two technologies makes for a more robust and safe aircraft system.

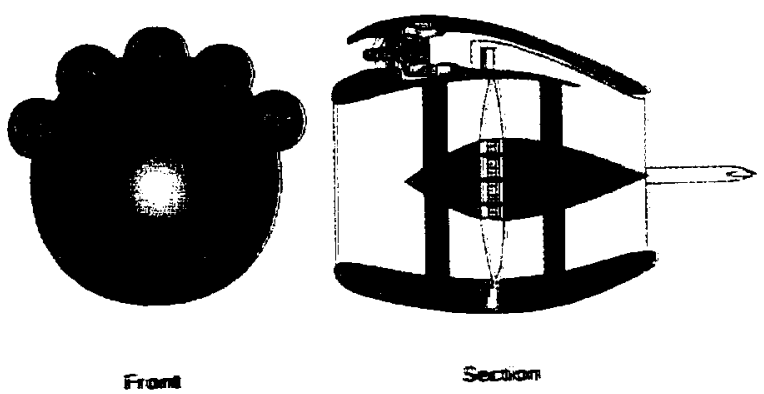

Fig. 25 Multi-Gas Generator Fan with Circulation Control Nacelle

\section{Concluding Remarks}

NASA Langley has a long-standing research effort in separation control for high-lift systems that includes both passive and active approaches. The current emphasis has shifted to unsteady methods for active flow control, and the two approaches currently under development include oscillatory blowing for separation control and pulsed circulation control technology.

The active separation control research has taken the technology from low Reynolds number laboratories to Reynolds numbers representative of flight conditions. The results to date have examined both leading edge and flap separation control, Mach effects and sweep effects (e.g. infinite sweep). The lift benefits of active separation control had no significant Reynolds number effects. Oscillatory excitation was shown to be two orders of magnitude more effective than steady excitation. The results were shown to be sensitive to 
Mach effects, and understanding the flow physics was essential to placing the blowing slots at the optimum location. Langley is presently attempting to extend the results from the simple airfoils previously tested to a modern supercritical airfoil with drooped leading edges and a simple trailing edge flap. The results for the drooped leading edge look very promising but more work is required to address flap separation control at high flap deflection angles.

The performance of the pulsed Circulation Control blowing system realized a $50 \%$ reduction in required mass flow for a given lift coefficient. This result alone opens a window of opportunity for potential advanced pneumatic systems that have been shown to exceed the performance of conventional high lift systems. Variations in the duty cycle at a given frequency highlighted the controllability of the performance with small bursts of high-speed air. Continued research is necessary to quantify the overall system time dependent response of the airfoil including the leading edge and internal plenums. The GACC airfoil has been proven to be an excellent test bed for the multi-functional circulation control study that can operate as a high lift system, a pneumatic aileron, and a high-speed air brake. Follow-on testing is expected to improve the database for CFD validation and the understanding of the flow physics related to circulation control concepts.

The tight coupling of advanced flow control and propulsion systems is an inevitable solution for vehicles with optimum "system" performance. The ability to impact global objectives, such as enhanced mobility that permits travel further, faster, anywhere, anytime, can not be understood in terms of advanced technologies alone. For NASA, the challenge is to develop technologies that spur significant improvements. Clearly, from statistical data of travel trends and average speeds, the hub and spoke, and highway systems are approaching their limits in many sections of the market over the next 20 years. At these transition times, there is an especially great need to understand how advanced technologies can create a new solution space that opens up revolutionary, new capabilities instead of mearly trying to maintain what is daily being lost. One key parameter that helps define these new solution spaces in aeronautics is the speed range of vehicles, that is, the ratio of cruise speed to takeoff speed. Reaching new levels of this ratio will permit tremendous new mission capabilities for vehicles that takeoff and land in very limited spaces, and at the same time have smaller wing structures more nearly optimum for cruise performance. Flow control research at NASA is the avenue for achieving radical improvements to this parameter, as well as other key metrics in efficiency, robustness, and cost.

\section{Acknowledgements}

The authors would like to gratefully acknowledge the outstanding collaboration between Avi Seifert of Tel Aviv University and LaTunia Pack of NASA Langley that provided the contributions and material for the active separation control research for high lift systems. The authors would also like to acknowledge the program managers who support the research efforts. The ASCoT Project is led by Long Yip, the Morphing Project is led by Anna-Maria McGowan, and the TCAT Program is led by James Pittman.

\section{References}

1 "The NASA Aeronautics Blueprint - Toward a Bold New Era of Aviation", 3 Jun. 2002, http://www.aerospace.nasa.gov/aero blueprint/index.html

2 Washburn, A. E., Gorton, S. Althoff, and Anders, S. G.: "Snapshot of Active Flow Control Research at NASA Langley", AIAA Paper 2002-3155, AIAA 1 $1^{\text {st }}$ Flow Control Conference, St. Louis, MO, 24-27 June 2002

3 Gad El Hak: "Flow Control: Passive, Active, and Reactive Flow Management", Cambridge University Press, 2000

4 Lin, John C.: "Control of Turbulent Boundary Layer Separation using Micro-Vortex Generators", AIAA Paper 99-3404, 30th AIAA Fluid Dynamics Conference, Norfolk, VA, 28 June1 July, 1999.

5 Greenblatt, David, and Wygnanski, Israel, J.: "The Control of Flow Separation by Periodic Excitation", Progress in Aerospace Sciences 36 (2000) 487-545

6 Seifert, A., and Pack, L. G.: "Oscillatory Control of Separation at High Reynolds Number", AIAA Paper 98-0214, AIAA Aerospace Sciences Meeting \& Exhibit, 36th, Reno, NV, Jan. 12-15, 1998

7 Seifert, Avi, and Pack, LaTunia G.: "Oscillatory Excitation of Unsteady Compressible Flows over Airfoils at Flight Reynolds Numbers", AIAA Paper 99-0925, Aerospace Sciences Meeting and Exhibit, 37th, Reno, NV, Jan. 11-14, 1999

8 Seifert, Avi, and Pack, LaTunia: "Active Control of Separated Flows on Generic Configurations at High Reynolds Numbers", AIAA Paper 99-3403, AIAA Fluid Dynamics Conference, 30th, Norfolk, VA, June 28-July 1,1999 
9 Pack, LaTunia, and Seifert, Avi: "Dynamics of Active Separation Control at High Reynolds Numbers", AIAA Paper 2000-0409, AIAA Aerospace Sciences Meeting and Exhibit, 38th, Reno, NV, Jan. 10-13, 2000

${ }_{10}$ Seifert, Avi, and Pack, LaTunia G.: "Sweep and Compressibility Effects on Active Separation Control at High Reynolds Numbers", AIAA Paper 2000-0410, AIAA Aerospace Sciences Meeting and Exhibit, 38th, Reno, NV, Jan. 10-13, 2000

1 Seifert, Avi, and Pack, LaTunia G.: "Separation Control at Flight Reynolds Numbers: Lessons Learned and Future Directions", AIAA Paper 2000-2542, Fluids 2000 Conference and Exhibit, Denver, $\mathrm{CO}$, June 19.22, 2000

12 Pack, LaTunia, G., Schaeffler, Norman W., Yao, Chung-Sheng, and Seifert, Avi: "Active Control of Flow Separation from the Slat Shoulder of a Supercritical Airfoil", AIAA Paper 2002-3156, AIAA 1st Flow Control Conference, St. Louis, MO, 24-27 June 2002.

13 McLean, J.D., Crouch, J. D., Stoner, R. C, Sakurai, G. E., Seidel, G. E., Feifel, W. M., and Rush, H. M.: "Study of the Application of Separation Control by Unsteady Excitation to Civil Transport Aircraft", NASA CR-1999209338, June 1999

14 Ladson, C. A. and Ray, E. J.: "Evolution, Calibration, and Operational Characteristics of the Two-Dimensional Test Section of the Langley 0.3-meter Transonic Cryo Tunnel", NASA TP-2749, 1987.

15 Rallo, R. A., Dress, D. A., and Siegle, H. J. A.: "Operating Envelope Charts for the Langley 0.3-meter Transonic Cryogenic Wind Tunnel", NASA TM-89008, 1986

${ }^{16}$ Lin, J. C. and Dominik, C. J.: "Parametric Investigation of a High-Lift Airfoil at High Reynolds Numbers", Journal of Aircraft, Vol. 33, No. 4, 1997, pp. 485-491.

17 Jones, G. S., Viken, S. A. Washburn, A.E. Jenkins, L. N. Cagle, C.M., "An Active Flow Circulation Controlled Flap Concept for General Aviation Aircraft Applications," AIAA Paper 2002-3157, 1 ${ }^{\text {st }}$ AIAA Flow Control Conference, St. Louis, MO, 24-27 June, 2002

18 Wood, N., and J. Nielson, "Circulation Control Airfoils Past, Present, and Future," AIAA Paper 850204, January, 1985.
19 Englar, R.J., Circulation control Pneumatic Aerodynamics: blown force and Moment Augmentation and Modifications; Past, Present, \& Future", AIAA 2000-2541, June 2000.

${ }^{20}$ Liu, Y., Sankar, L.N., Englar, R.J., Ahuja, K.K., "Numerical Simulations of the Steady and Unsteady Aerodynamic Characteristics of a Circulation control Wing Airfoil," AIAA 2001-0704, January 2001

21 Metral, A.R., "On the Phenomenon of Fluid Veins and their Application, the Coanda Effect," AF Translation, F-TS-786-RE, 1939

22 Schlichting, H., "Boundary Layer Theory", page $750-751,2^{\text {nd }}$ Edition, 1979

23 Cagle, C.M., Jones, G.S. "A Wind Tunnel Model to Explore Unsteady Circulation Control for General Aviation Applications, AIAA 2002-3240, $1^{\text {st }}$ AIAA Flow Control Conference, St. Louis, MO, 24-27 June, 2002

${ }^{24}$ Rose, R.E., Hammer, J.M., \& Kizilos, A.P., "Feasibility Study of a Bi-directional Jet Flap Device for Application to Helicopter Rotor Blades," Honeywell Document No. 12081. FR1, July 1971

25 Englar, R.J., Williams, R.M., "Design of a Circulation Control Stern Plane for Subma. rine Applications," NSRDC Technical Note AL-200, March 1971

${ }^{26}$ Schaeffler, N.W., Hepner, T.E., Jones, G.S., Kegerise, M.A., "Overview of Active Flow Control Actuator Development at NASA Langley Research Center," AIAA 2002-3159, $1^{\text {st }}$ AIAA Flow Control Conference, St. Louis, MO, 24-27 June 2002

${ }^{27}$ Pasamanick, Jerome, "Langley Full-ScaleTunnel Tests of the Custer Channel Wing Airplane," NACA RM L53A09, National Advisory Committee for Aeronautics, April, 1953

28 Englar, Robert J., and Campbell, Bryan A.: "Pneumatic Channel Wing Power-Lift Advanced Super-STOL Aircraft", AIAA Paper $2002-3275,1^{\text {st }}$ AIAA Flow Control Conference, St. Louis, MO, 24-27 June, 2002

29 Englar, Robert J., and Campbell, Bryan A.: "Pneumatic Channel Wing Power-Lift Advanced Super-STOL Aircraft", AIAA Paper 2002-3275, 1st AIAA Flow Control Conference, St. Louis, MO, 24-27 June, 2002 